\title{
Social Work with Immigrants in Kazakhstan as Means of Prevention of the Social Conflicts in Society
}

\author{
Asylkhan Yessilov \\ Academy of Public Administration under the President of Republic of Kazakhstan \\ Abay street 33 a, Astana, 010000, Kazakhstan; Email: esilov@gmail.com
}

\section{Doi:10.5901/mjss.2015.v6n5s3p259}

\section{Abstract}

\begin{abstract}
Kazakhstan being one of the engines of social and economic development in the Eurasian region becomes the center of gravity for immigrants. The state immigration policy is directed at the involvement of immigrants - ethnic Kazakhs. At the same time, stability of the Kazakhstan society is a pledge for further development of the state and society. The main problematic issues of adaptation of immigrants in the Kazakhstan society are analyzed. Now we are not witnesses of the serious conflicts of immigrants, but at the same time, existing problematic issues of adaptation of immigrants suggest the idea of preventives of the social conflicts in the Kazakhstan society. Immigrants at the low extent of social and economic adaptation can be catalysts of social tension and the conflicts. Social work in modern understanding is activity for the improvement of social and economic living conditions of the segments of the population, which are in the difficult life situation. The possible strategy of preventives of the social conflicts by application of technologies of social work is offered.
\end{abstract}

Keywords: social work, social conflict, prevention, immigrant, technologies of social work, Kazakhstan.

\section{Introduction}

The social conflicts are the integral part of the natural development of any state and that litmus piece of paper allowing judging the processes happening in society. However, it is necessary to make a reservation that the social conflicts, as well as any conflicts, in general, happen two types: constructive and destructive. The first type is inherent in any civilized society living within precepts of law and promotes its development. The second type, which is the destructive social conflict is inherent to a society where often there is the crisis of legitimacy of the political system, and conducts to long stagnation in society.

If to take the view of the past and the present, it is possible to see that after disorder of the Soviet Union among the CIS countries the only island of stability, which managed to avoid sharp shocks and cataclysms in the social sphere, without exaggerations there, is Kazakhstan.

Stability of the Kazakhstan society is its firm basis for further social and economic development. Today in the world, there are no states with absolute stability, lack of the conflicts. True is also that fact that today there are no such technologies allowing eliminating the conflicts and social tension. Throughout all existence of humankind took contradiction place, so and the conflicts.

In the certain degree, the conflicts are the basis for the subsequent development of society. So, according to $\mathrm{L}$. Kozer "The conflict not always dysfunctional about system in which it arises; often the conflict is necessary for its preserving" (Kozer, 2000, p. 71).

In turn at the turn of the millennia, the conflicts began to be perceived as a threat to stability of society and provoking of social tension. During this period, the increased interest in the development of technologies for prevention of the conflict from representatives is noted as sciences and the states.

Kazakhstan in this plan is the stability island on the Eurasian continent. Indisputable is that fact that for years of independence in Kazakhstan was not noted the serious social conflicts.

Now technologies of conflict prevention are well known in science, nevertheless, still there is no the accurate, unified determination of the term "conflict prevention".

For the purpose of the exception of the difference of determinations of this concept, we will offer the formulation. So, at the heart of prevention of the conflict there is the principle of preventives which consists in activities for decrease in social tension, identification of contradictions and elimination of the factors promoting emergence of the conflicts at early stages of emergence. 
It is undoubted that activities for conflict prevention demand serious efforts and means as from the state, and representatives of science and civil sector. Moreover, such activity is not foreseeable the nonprofessional look though it affects all spheres of life activity of society. So known konfliktolog Johannes Varvik writes: "If the conflict manages to be avoided, practically do not speak about success of preventive measures as in sense of unambiguous relationships of cause and effect it is seldom possible to prove, what measure led to that crisis or the conflict was settled and escalation of violence did not take place" (Varvik, 2010, p. 6).

\section{Research Methodology}

In this article, we will try to consider technologies of social work in the prevention of the social conflicts connected with immigrants. In research such methods as the analysis of the documents regulating immigration of ethnic Kazakhs to Kazakhstan and official statistical data, and also materials the interviews to immigrants conducted by the author during the period from November 1, 2014 to May 1, 2015 were applied.

\section{The Compositional Part}

Functional characteristics of the social sphere give the grounds to define social work as the special mechanism promoting adequate estimation and the competent solution of social problems of society. The purpose of social work - satisfaction of the guaranteed interests and requirements of different groups of the population, creation of the conditions promoting improvement of social, psychological and physical well-being of the personality (Belinsky, p. 5).

Proceeding from the geographical position and successful economic development, Kazakhstan gradually becomes one of the centers of gravity of migrants.

The essential feature of migration policy of Kazakhstan is its focus on repatriation - return of the ethnic Kazakh population to the country with receipt of nationality. According to the legislation ethnic Kazakhs - repatriates from now on are referred to as oralmana.

The state migration policy proceeds from the need of conducting purposeful system work for the purpose of successful adaptation oralman appeared in other social and cultural environment. It is possible to note that this perspective is rather actual for the safety of Kazakhstan, as the countries.

During the conducted sociological research, it was revealed that essential barriers in social and economic adaptation oralman are questions of education and according to employment.

Here, it would be desirable to stop on issues of education and employment of ethnic migrants as essential, influencing their integration and adaptation into the Kazakhstan society. The question of repatriation for Kazakhstan became significant since 1991, after the formation of the independent state, in connection with the amplified outflow of the Russian-speaking population and reduction of population, including radical.

Thus, again arisen state suggested the ethnic Kazakhs living abroad to return to the historic homeland. So, according to Ministry of health and social development of the Republic of Kazakhstan from 1991 to January 1, 2015 on the historical homeland returned, and received the status of the oralman of 259159 families or 952882 ethnic Kazakhs (in 2014 - 3792 families or 8247 ethnic Kazakhs) that makes 5,5\% of the total number of the population of the country (Internet site of Ministry of health and social development of the Republic of Kazakhstan, www.mzsr.gov.kz.).

In the first years, moving of repatriate's immigrants passed evenly across all territory of the country taking into account the social and economic situation in regions. However, in the 2000th year's process of their secondary resettlement, now within the country, for example from northern regions in southern, owing to climatic and cultural conditions began. Also, the process of resettlement to the large cities, in the so-called centers of gravity, in connection with higher employment possibilities began a bit later. Information on moving oralman on $01.01 .2015 \mathrm{It}$ is shown in Figure 1. 


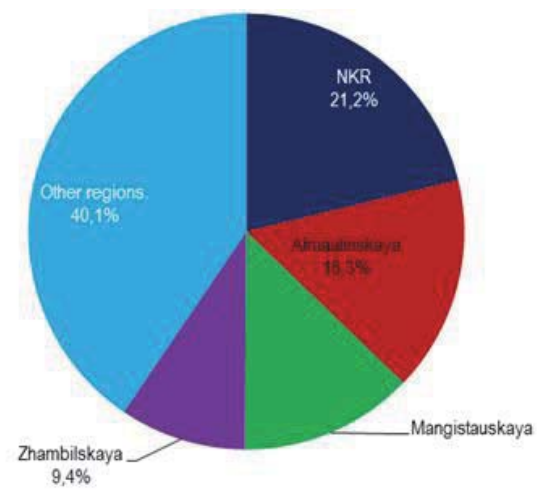

Figure 1 - Information on moving oralman on 01.01 .2015

The greatest number oralman is observed in the Southern Kazakhstan, Almaty and Mangistausk areas where more than $50 \%$ of all families oralman lives. However, in 2005 lived nearly $65 \%$ of newcomers of repatriates in these areas. Here it is possible to note that migration policy yielded the fruits, new workplaces, questions of allocation of lands in the regions having a deficiency in the manpower were created. Such processes as independent movements create an additional load of local executive bodies, of social infrastructure, including of healthcare institutions and educations. The process of secondary resettlement brought spontaneity elements aggravated not adjustability of migratory processes in Kazakhstan (Esilov and Kalashnikova, 2015).

To immigrants, questions of education and advanced training seem not important for successful socialization.

One of the repatriation purpose to the author completion of a deficit of the workforce within the process of diversification of economy and industrialization of the country seems. According to Kazakhstan education level and qualification of future citizens of the country, is important.

Kazakhstan is the participant of seven basic international human rights agreements of the UN, including the International Covenant on Economic, Social, and Cultural Rights. According to these agreements the state assumed the obligation to accept within the available resources the adequate legislative, administrative, judicial and other measures to gradually to reach full implementation of the right to education.

It would be desirable to note that according to the education level Index - the combined indicator of the Program of Organization Development of the United Nations (PODUN) calculated as the index of literacy of adult population and the index of the cumulative share of the pupils getting the education Kazakhstan is in the countries of the world (Education Index) on the 35th place from 188 states of the world. That is rather high recognition of education of our country at global level.

The basis is allowing migrants to get the education in Kazakhstan the Law of the Republic of Kazakhstan "About population shift" is. Therefore, article 23 of the Law contains the regulations connected with education. According to them, the persons which received the status of the oralman and members of their families are provided with places at schools and the preschool organizations on an equal basis with citizens of the Republic of Kazakhstan, possibility of education according to the allocated quota on receipt in the educational organizations of technical and professional, postsecondary and higher education in the quantity determined by the Government of the Republic of Kazakhstan.

Education is one of the components of social and economic adaptation of ethnic Kazakhs and today there is the number of negative factors in this process.

The first, this legal support of the process of repatriation, which substantially influences receipt of nationality, provision of housing, employment oralman. The status of the oralman is intermediate and in the legislation of Kazakhstan, in particular in labor the rights and duties are not reserved for this status. There is no special legal regime for recognition by their nonresidents of RK, Information on employment oralman (as of 01.01.2014) It is shown in Figure 2. 


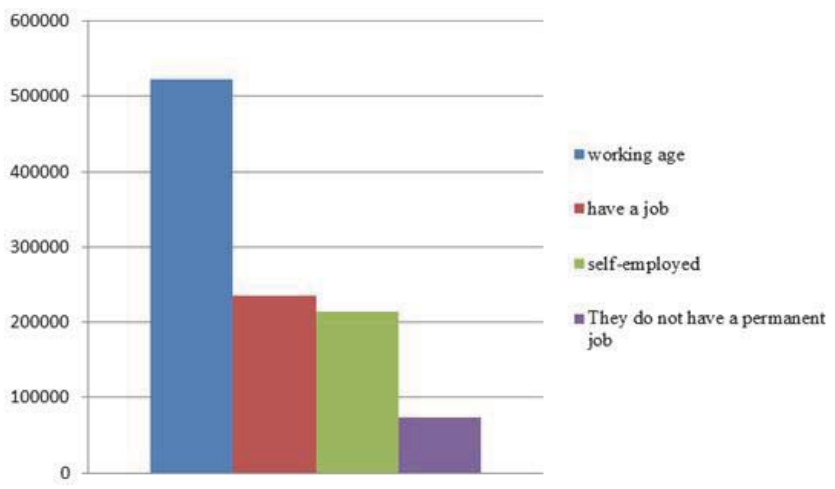

Figure 2 - Information on employment oralman (as of 01.01.2014)

From this chart, we see that only the half oralman, working-age have a permanent job. The certain part is self-busy (generally, these people conduct the economy, generally in rural areas). 14.2 the $\%$ of the number of working-age have no permanent job, are killed by seasonal or temporary earnings.

To the half of the ethnic Kazakhs who returned to Kazakhstan cannot get the job at once. Moreover, of course, the reason of it seems in not only education level and qualification.

The analysis of education level oralman working-age revealed the following. If in 2001 among repatriates was doctors of science -13 , candidates of science - 67. 12182 persons, unfinished the highest -1472 , specialized secondary - 16196 E.Yu. Sadovskaya (2001) had the higher education, for January 1, 2014 these indicators look as follows, doctors of science -77 , candidates of science - 223. 45760 people, specialized secondary -107597 , the general average - 319295, not having initial, including not having education - 51989 (Internet site of Ministry of health and social development of the Republic of Kazakhstan, www.mzsr.gov.kz) have the higher education.

The second is the language barrier that is the significant factor of economic integration oralman. In northern regions ignorance of Russian, in southern its distinctions of writing is the problem. So, for example, the oralmana that arrived from China of Pakistan use the Arab writing, from Uzbekistan and Turkey Latin. Thus, ignorance of both languages and writing leads to that to the oralman impracticable to find a job.

Here it is possible to allocate that lack of common language for forming of cross-cultural dialog and distinction in mentalities and some other factors leads to increase in intensity between oralmana and aboriginals of the country.

The third, the essential factor of the low level of social and economic integration, is a distinction in education systems in Kazakhstan and the country of the outcome. Many oralmana have no opportunity to find a job in the specialty, having thus the higher education, generally engineers, technologists, doctors, economists, lawyers. From here, two problems follow: first, a discrepancy of the profession, secondly, many oralmana are forced to interrupt the career in the country of the outcome that forces them to reduce the professional and social status.

The majority oralman working-age have the general secondary education. However, at the same time the share of those who has secondary special or higher education is rather small. That is we can claim that owing to the qualification and education, in the majority of the oralmana are not occupied at highly skilled work, respectively they receive not the high salary that can be one of the reasons of defective social and economic adaptation. The low income influences the security of families of migrants, and respectively the standard of living. The comprehensive program of advanced training and education level of this category is necessary.

Availability of permanent job can be considered as one of the conditions of successful adaptation to the new environment. However, the level of the hidden unemployment in the environment oralman is considerable today.

Thus, it is possible to claim that one of the reasons of the conflicts of migrants is - unemployment. Unemployment is the social problem that needs to be solved for the state.

Return of ethnic Kazakhs to the historic homeland testifies to the solvency of our state. The economic situation and the social policy realized in our country attract immigrants.

Today are provided to arrange independently perspectives the life on the new place, to find work, to receive in case of need new specialty, in general, to participate in all transformations happening in our country.

In it, the direct role is played by certain technologies of social work. In social work with migrants we allocate three 
life sphere components through which are performed naturalization, adaptation, acculturation of immigrants: naturally anthropological (demographic, territorial, settlement, ethnoanthropological), spiritual and cultural (educational, confessional, national and cultural), agent-professional "employment, labor market, professional and entrepreneurial structure" ( Akmalova and Kapitsyn, 2008).

\section{Recommendations}

Let's consider technologies of social work with migrants, applicable in Kazakhstan and necessary for the implementation of the state social policy concerning this group of the population.

1. The social direction (work is carried out in contact with different departments) includes:

- carrying out social consultations;

- carrying out actions for social rehabilitation in stationary and non-stationary conditions;

- Social diagnostics;

- Prevention of deviant behavior;

- The organization of cultural and leisure work with aged and disabled people from among migrants;

- Homelessness prevention (including assistance in receipt of the hostel, temporary housing or acquisition of own housing);

- Prevention of children's homelessness (including the device of children in orphanages and houses nursing homes);

2. The social and information direction (work is carried out in contact with mass media):

- informing migrants on activity of social services;

- Collection of information about migrants (including from migrants) and its systematization for the purpose of the organization of optimum social work with this category of the population;

- informing the public concerning problems of migration and migrants (mainly through mass media) for the purpose of the establishment by migrants of stable social relations;

- Assistance to adequate lighting in mass media on the subject of migration.

3. The social and psychological direction (work is carried out in contact with educational bodies and health care):

- psychological consultation;

- psychological correction and help in social adaptation;

- psychological assistance in critical crisis situations and conditions of the post-traumatic stress;

- psycho prevention of the stress;

- carrying out psychological training with migrants;

- training in auto-trainings and psychological self-control;

- $\quad$ psychological diagnostics of the development of children and teenagers from families of migrants;

- $\quad$ psychological diagnostics and consultation in the field of acquisition of new specialty.

4. The social and pedagogical direction (work is carried out in contact with educational bodies, health care and the law and order):

- carrying out consultations concerning the family and to the education of children;

- social and pedagogical work with children and teenagers;

- $\quad$ the specialized (correctional) social and pedagogical help to the children and teenagers needing it;

- $\quad$ the social and pedagogical help to the children and teenagers having problems in training;

- control of education by children and teenagers from families of migrants;

- professional consultation and assistance to vocational training by teenagers and youth from among migrants;

- prevention of deviant behavior;

- carrying out leisure actions for children and teenagers directed on adaptation in new conditions.

5. The social and legal direction (work is carried out in contact with judicial and law enforcement agencies):

- protection of the rights of migrants;

- $\quad$ providing to migrants information on their rights and duties;

- social and legal consultation.

6. The medico-social direction (work is carried out in contact with medical authorities):

- medico-social consultation;

- rendering pre-medical medical care; 
- assistance in carrying out a medical examination of migrants;

- control of adequate sanitary scheduled maintenance and observance of regulations of social hygiene;

- $\quad$ the help in the acquisition of policies of insurance medicine (issue of the certificate on medical care);

- identification of chronic patients and disabled and the organization for them specialized medico-social consultations;

- $\quad$ social and psychiatric diagnostics and help;

- $\quad$ rendering assistance in the acquisition of drugs and other medical means;

- $\quad$ if the necessary allocation of financial aid to treatment;

- $\quad$ the direction in specialized medical institutions;

- control of the sanitary condition of housing of migrants.

7. The financial direction - rendering the starting help (providing loans):

- providing financial aid on the basis of the principle of the individual approach to each particular situation.

8. Social and economic direction:

- consultation on social and economic problems;

- providing help in the achievement of economic independence;

- assistance in an increase of the income.

9. The material direction (work is carried out in contact with public organizations):

- providing the product help;

- providing the ware help;

- $\quad$ providing other natural help (medicine, construction materials, etc.).

10. The social and labor direction (work is carried out in contact with employment services):

- rendering assistance in receipt of the main and extra work;

- rendering assistance in opening of the own case;

- consultation on questions of work, employment, and career guidance;

- help in professional training and retraining.

\section{Conclusion}

Today world experience testifies that by means of social technologies (information, training, implementation, political, managerial, etc.) it is possible to resolve timely the social conflicts, to remove social stress, to prevent accidents, to block risky situations, to accept and carry out optimum management decisions, etc. [Technologies of social work, 2002, p. 13).

Immigrants are the integral part of the Kazakhstan society, and it is necessary to make efforts for due social and economic adaptation. The level of adaptation of immigrants is higher, the amount of their potential conflicts is lower. This work shall be conducted as from state bodies, and civil sector. Moreover, of course, one of the decisive factors of adaptation is the attitude towards immigrants from indigenous people, the culture of tolerance is necessary.

\section{Acknowledgement}

The author expresses gratitude for assistance in writing of article to Professor of the Sofia University of St. Clement of Ohrid Tatyana Dronzina and Professor of Academy of Public Administration under the President of Republic of Kazakhstan Natalya Kalashnikova.

\section{References}

Kozer, L. (2000) Functions of the social conflict / Lane to English O. A. Nazarova. M.: Ideya-Press.

Varvik, Johannes (2010). Prevention of wars and preservation of peace. Search of well-tried remedies of conflict prevention//Internationale Politik. Prevention of the conflicts or intervention. 2002. No. 11-12.

Belinsky, A.B. Konfliktologiya in social work: Manual / A.B. Belinskaya. - M.: Publishing and trade corporation "Dashkov and To *". pp. 224.

Internet site of Ministry of health and social development of the Republic of Kazakhstan www.mzsr.gov.kz. Date of last visit 05.04.2015.

Yessilov, A.B. and Kalashnikova N.P. (2015). Technologies of social work with elderly migrants: international experience and Kazakhstan practicel/ Advances in gerontology. T.28. No. 2. pp. 360-365.

Sadovskaya, E.Yu. (2001) Migration in Kazakhstan at the turn of the XXI century: main tendencies and perspectives. Almaty.

Akmalova, A.A. and Kapitsyn V.M. (2008) Social work with migrants and refugees: Manual / Otv. edition P. D. Pavlenok. M.: INFRA-M. pp. 220.

Technologies of social work (2002): The textbook under the general editorship of E.I. Holostova prof. M.: INFRA-M. pp. 400. 